\title{
Fas (CD95/Apo-1)/Fas Ligand Expression in Neonates with Pontosubicular Neuron Necrosis
}

\author{
FRANK K.H. VAN LANDEGHEM, URSULA FELDERHOFF-MUESER, AXEL MOYSICH, \\ CHRISTINE STADELMANN, MICHAEL OBLADEN, WOLFGANG BRÜCK, AND \\ CHRISTOPH BÜHRER
}

Institute of Neuropathology [F.K.H.v.L., C.S., W.B.], and Department of Neonatology [U.F.-M., A.M., M.O., C.B.], Charité, Campus Virchow Klinikum, Humboldt University, Augustenburger Platz 1, D-13353 Berlin, Germany

\begin{abstract}
ABST
Pontosubicular neuron necrosis (PSN) represents an age-
specific response to severe hypoxic-ischemic injury occurring in
human neonates but not in older children or adults. Histologi-
cally, PSN is characterized by acute neuronal death in the pontine
nuclei and the hippocampal subiculum bearing the hallmarks of
apoptosis. In animal models of hypoxic-ischemic injury, induc-
tion of neuronal apoptosis can be triggered by Fas (CD95/Apo-
1), a cell surface receptor of the tumor necrosis factor- $\alpha$ super-
family, which transduces apoptotic death signals when cross-
linked by its natural ligand. Here, we have investigated the
expression of Fas/Fas ligand in human autopsy material consist-
ing of 13 PSN cases and 10 age-matched cases without PSN.
Terminal deoxynucleotidyl transferase-mediated dUTP nick-end
labeling, immunohistochemistry, and double labeling for Fas/Fas
ligand and the astrocyte marker glial fibrillary acid protein, the
microglia/macrophage specific marker KiM1P, and the neuronal
marker NeuN were performed on formalin-fixed brain speci-
\end{abstract}
PSN, originally described by Friede in 1972 (1), is considered to be a form of perinatal brain damage with characteristic acute neuronal death in the basal pontine nuclei and the subiculum of the hippocampus. The lesions are not evident on gross inspection of the cut brain. Microscopic findings consist of neuronal death with loss of definition of the cell membrane (necrosis), karyorrhexis (loss of the nuclear membrane), and eosinophilic staining of the cytoplasm. Recently, the later defined morphologic hallmarks of programmed cell death, or apoptosis, such as chromatin condensation, margination, karyorrhexis, DNA breakdown, and formation of apoptotic bodies,

Received March 3, 2001; accepted August 21, 2001.

Correspondence and reprint requests: Ursula Felderhoff-Mueser, M.D., Department of Neonatology, Charité, Campus Virchow Klinikum, Humboldt University, Augustenburger Platz 1, D-13353 Berlin, Germany; e-mail: ursula.felderhoff@charite.de

FKHVL and UF-M contributed equally to the work. mens. Although mainly neurons of both PSN and controls expressed Fas receptor, expression was significantly increased ( $p=$ $0.001)$ in PSN cases in which predominantly degenerating cells with signs of early apoptosis showed Fas expression. In contrast, Fas ligand expression was found mainly on astrocytes and microglial cells. There was no significant difference between cases with and without PSN. We conclude that in the developing human brain, cells expressing the Fas receptor may be susceptible to undergoing apoptosis in response to hypoxic-ischemic injury. (Pediatr Res 51: 129-135, 2002)

\section{Abbreviations}

PSN, pontosubicular necrosis

HII, hypoxic-ischemic injury

TUNEL, terminal deoxynucleotidyl transferase-mediated

dUTP nick-end labeling

GFAP, glial fibrillary acid protein have been described in these particular brain regions $(2,3)$. PSN lesions are usually observed in newborns ranging from 30 weeks of gestational age up to 2 months. They often coexist with other forms of perinatal damage including hemorrhages, infarcts, periventricular leukomalacia, and kernicterus. Most severe lesions are seen in newborns with a history of asphyxia, heart failure, and severe pulmonary morbidity (1-3).

Apoptosis is known to be a major mechanism of neuronal loss after HII to the developing brain and has been widely investigated in animal models (4-6) and human infants (7). To study the process of human neuronal cell apoptosis after HII to the developing CNS, PSN serves as a model system (2).

In the context of HII, apoptosis can be triggered by diverse signals including the removal of survival factors, DNA damage resulting from free radical generation, reduced intracellular ATP levels, modulation of immunomolecules, and the activa- 
tion of proapoptotic receptors including tumor necrosis factor- $\alpha$ receptor in the plasma membrane $(8-10)$. Fas (CD95/ Apo-1), a member of the tumor necrosis factor- $\alpha$ receptor superfamily, is situated on the cell surface and transduces apoptotic death signals when cross-linked by its natural ligand or by agonist antibodies. Receptor aggregation follows Fas ligand binding or antibody cross-linking, which leads to the formation of a death-inducing signaling complex, downstream activation of caspases, and, finally, execution of the apoptotic program $(11,12)$. Fas signaling has further been shown to trigger via different intracellular pathways for proliferation, cell differentiation, maintenance of the immune response, and immune privilege, and also an alternative cell death pathway leading to necrosis (13-17). The Fas gene also seems to play a pivotal role during brain development $(18,19)$.

Furthermore, Fas has been shown to be expressed under pathologic conditions in neurodegenerative disorders such as Alzheimer's disease and multiple sclerosis $(20,21)$. HII leads to Fas activation both in the adult and the immature rat CNS $(22,23)$. The marked up-regulation of Fas after cerebral HII to the developing rodent brain (23) led us to investigate its role in a human model of HII.

In this study we have demonstrated the expression of Fas and its ligand by immunohistochemistry in formalin-fixed and paraffin-embedded human autopsy material consisting of 13 PSN cases and 10 cases without detectable neuropathologic alterations.

\section{METHODS}

Human tissue specimens. The present study is based on 13 autopsy cases of PSN, four stillborn and nine liveborn, five female and eight male, collected in the Institutes of Neuropathology at the University of Göttingen (1996-1998) and the Humboldt University in Berlin (1998-1999). The infants were born at a median gestational age of $40 \mathrm{wk}$ (range, 23-41 wk) and survived for a median of $1 \mathrm{~d}$ (range, 0-28 d). Informed parental consent was obtained for autopsy. Autopsies were performed within $24 \mathrm{~h}$ postmortem. Brains were removed and fixed in buffered $4 \%$ formaldehyde for $10 \mathrm{~d}$. Tissue samples were routinely paraffin embedded, subsequently cut in $4-\mu \mathrm{m}$ sections, stained with hematoxylin and eosin, and further subjected to TUNEL and immunohistochemistry with double labeling. Histologic examination included the frontal and parietal neocortex, basal ganglia, hippocampal regions, cerebellum, midbrain, pons, and medulla oblongata.

Only cases exhibiting the typical hallmarks of PSN in the pontine nuclei and subiculum as defined by Friede in 1972 (1) were included in this study. The pons and the hippocampus of 10 cases without the histologic hallmarks of PSN or other detectable neuropathologic alterations served as control tissue. Although some of these autopsy cases had a history of severe illness, no other signs of perinatal brain damage, often coexisting with PSN, such as intraventricular hemorrhages, kernicterus, or periventricular infarcts, were found. In addition, there were no histologic signs of necrosis or astrogliosis, often seen in asphyctic brains, in any other brain region.

Clinical, neuropathologic, and pathologic data are summarized in Tables 1 and 2 .

Immunohistochemistry. Sections were mounted on slides and fixed overnight at $37^{\circ} \mathrm{C}$. Subsequently they were dewaxed, rehydrated, and microwaved for $12 \mathrm{~min}$ in $10 \mathrm{mM}$ citrate buffer, $\mathrm{pH}$ 6.5, at $600 \mathrm{~W}$ (Bosch, Berlin, Germany) as previously described (24). Endogenous peroxidase activity was blocked by incubating sections with $0.6 \% \mathrm{vol} / \mathrm{vol}$ hydrogen peroxide for $15 \mathrm{~min}$ at room temperature. Subsequently sections were incubated with a 1:20 dilution of normal swine serum in PBS for $20 \mathrm{~min}$, and then incubated with either polyclonal goat anti-rabbit C 20 Fas antibody or N 20 Fas

Table 1. Summary of clinical, pathologic, and neuropathologic data in PSN patients

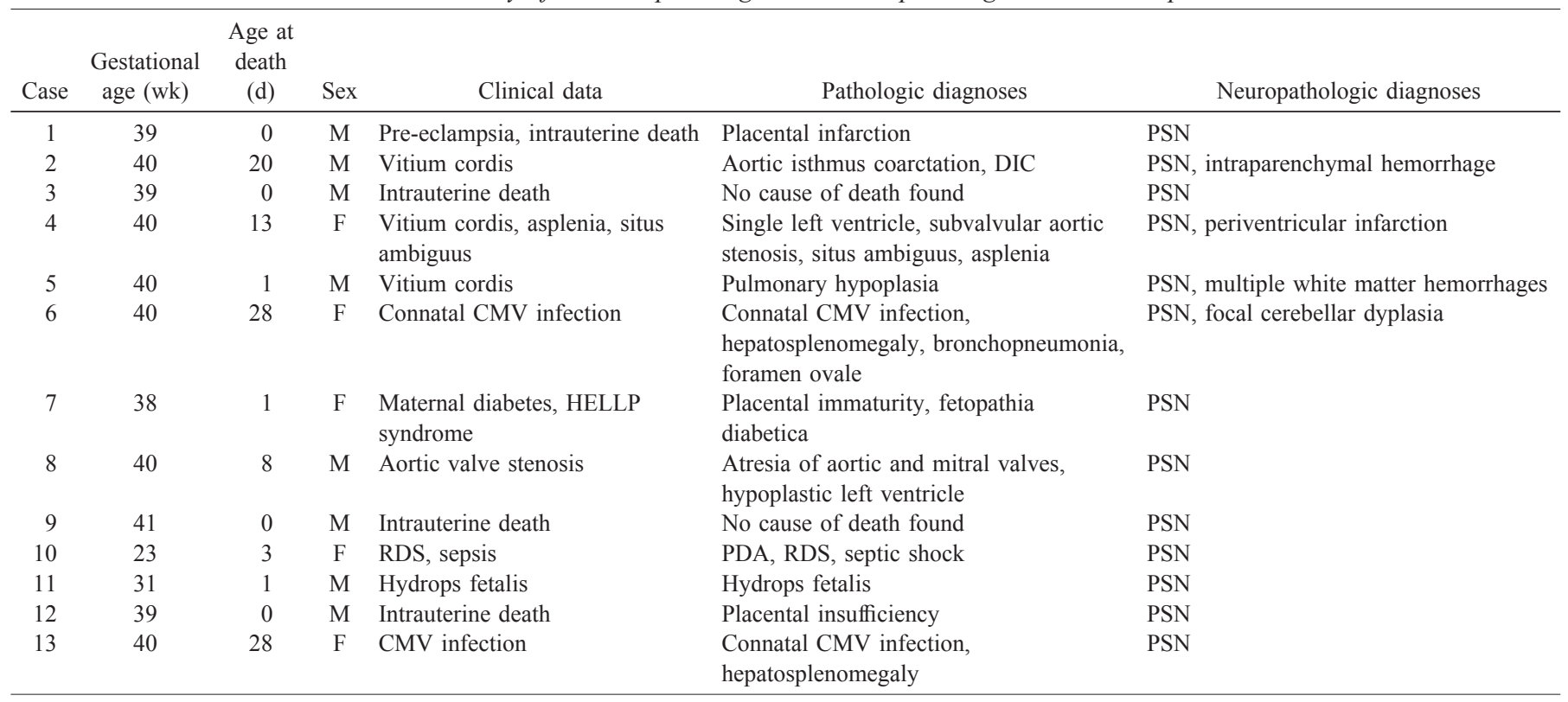

Abbreviations used: CMV, cytomegalovirus; DIC, disseminating intravascular coagulation; HELLP, hemolysis, elevated liver enzymes, and low platelet count; PDA, patent ductus arteriosus; RDS, respiratory distress syndrome. 
ligand antibody (Santa Cruz Biotechnology, Santa Cruz, CA, U.S.A.) diluted $1: 500$ and 1:250, respectively, in $10 \%$ fetal bovine serum in PBS. Sections were washed and treated with a swine anti-rabbit IgG (1:500; DAKO, Hamburg, Germany). After detection with the Vectastain ABC Elite kit (Vector Laboratories, Wertheim, Germany), positive cells were visualized with diaminobenzidine (Sigma Chemical Co., Deisenhofen, Germany). Nuclei were lightly counterstained with hematoxylin. For negative controls, the primary antibody was replaced by including the Fas/Fas ligand peptide immunogen as a competitor of antibody binding according to the manufacturer's instructions (Santa Cruz Biotechnology).

TUNEL and Fas double labeling. Terminal deoxynucleotidyl transferase-mediated incorporation of digoxigeninlabeled nucleotides was used to determine DNA fragmentation as previously described (24-26). Briefly, deparaffinized and rehydrated sections were pretreated with $5 \%$ proteinase $\mathrm{K}$ (Sigma Chemical Co.) in PBS for $15 \mathrm{~min}$ at $37^{\circ} \mathrm{C}$, followed by incubation with terminal deoxynucleotidyl transferase labeling mix $(10 \mu \mathrm{L}) 5 \times$ tailing buffer, $1 \mu \mathrm{L}$ of digoxigenin-labeled deoxynucleotides, $2 \mu \mathrm{L}$ of cobalt chloride $(25 \mathrm{mmol}), 12 \mathrm{U}$ of terminal transferase, and distilled water (added to a total volume of $50 \mu \mathrm{L}$ ) for $1 \mathrm{~h}$ at $37^{\circ} \mathrm{C}$. Alkaline phosphataseconjugated anti-digoxigenin Fab fragments (1:500) were applied for $1 \mathrm{~h}$. 4-Nitroblue tetrazolium chloride and 5-bromo4-chloro-3-indolyl-phosphate were used for visualization of the complex (Boehringer Roche, Mannheim, Germany). Double labeling with Fas was performed as described above, visualized by use of the alkaline-phosphatase-anti-alkalinephosphatase technique and lightly counterstained with hematoxylin. Sections were evaluated by light microscopy.

Fas/Fas ligand double labeling with GFAP, KiM1P, and NeuN. Sections were subjected to microwave treatment and incubated with Fas/Fas ligand primary antibodies as described above. Immunofluorescence was performed using goat antirabbit Cy3 (Dianova, Hamburg, Germany; dilution 1:50). For double labeling, mouse monoclonal GFAP (DAKO; dilution 1:250), KiM1P (kindly provided by Prof. H.J. Radzun, Göttingen, Germany; dilution 1:100), and NeuN (Chemicon, Hofheim, Germany; dilution 1:100) were used to identify astrocytes, microglia, and neurons, respectively. Immunopositive cells were visualized by goat anti-mouse Oregon Green (MoBiTec, Göttingen, Germany) binding. Evaluation was performed by fluorescence microscopy.
Morphometric analysis. Tissue sections of pons and hippocampus were semiquantitatively evaluated by light and fluorescence microscopy (Leica DMRB, Bad Bensheim, Germany) at high power magnification $(\times 1000)$ by two independent observers (F.K.H.v.L. and A.M.).

The total number of immunopositive cells (all cell types) was determined at a magnification of $\times 1000$ in 10 standardized microscopic fields of $0.01 \mathrm{~mm}^{2}$ each, as defined by an ocular morphometric grid. Evaluation was performed according to the number of positively stained cells and compared with cells with and without the morphologic hallmarks of nuclear apoptosis: normal chromatin, chromatin condensation, dense chromatin fragments, and apoptotic bodies.

Four groups of cells were evaluated: 1) apoptotic cells, 2) apoptotic cells with Fas/Fas ligand immunopositivity, 3) Fas/ Fas ligand-positive cells in the absence of apoptosis, and 4) cells without immunopositivity and without apoptosis. Cell numbers were determined in the ventral pontine nuclei at the anatomic level of the locus ceruleus and in the subiculum at the level of the lateral geniculate body.

For statistical evaluation the nonparametric Mann-Whitney $U$ test was applied, and $p<0.05$ was considered significant.

\section{RESULTS}

Autopsy findings. The clinical and neuropathologic findings of all cases with and without PSN included in this study are summarized in Tables 1 and 2. Hematoxylin and eosin staining and TUNEL were applied on tissue sections to examine the specimens morphologically and to confirm DNA fragmentation.

In cases of PSN, light microscopic evaluation of the hippocampal region and the pons revealed the key characteristics of PSN originally described by Friede (1). On hematoxylin and eosin staining, nuclei showed dense condensation of the chromatin, fragmentation of the collapsed nucleus into basophilic granules, and eosinophilic cytoplasm (Fig. 1). These findings were most prominent in the subiculum and the pontine nuclei. In earlier apoptotic stages, nuclei exhibited chromatin condensation deposited on the inner surface of the nuclear membrane (margination). Furthermore, similar apoptotic changes were found in the dentate gyrus and the CA1 region of the hippocampus. Astrocytic gliosis was observed in later stages of

Table 2. Summary of clinical, pathologic, and neuropathologic data in control subjects

\begin{tabular}{|c|c|c|c|c|c|c|}
\hline Case & $\begin{array}{c}\text { Gestational } \\
\text { age (wk) }\end{array}$ & $\begin{array}{l}\text { Age at death } \\
\text { (d) }\end{array}$ & Sex & Clinical data & Pathologic diagnoses & Neuropathologic diagnoses \\
\hline 1 & 39 & 0 & $\mathrm{~F}$ & Fetal death & Brain autopsy only & Normal \\
\hline 2 & 40 & 1 & M & Perinatal asphyxia & Brain autopsy only & Normal \\
\hline 3 & 40 & 50 & M & Sudden death & SIDS & Normal \\
\hline 4 & 40 & 49 & M & Sudden death & SIDS & Normal \\
\hline 5 & 40 & 70 & $\mathrm{~F}$ & Sudden death & SIDS & Normal \\
\hline 6 & 40 & 35 & M & Pneumonia & Pneumonia & Normal \\
\hline 7 & 40 & 70 & M & Pneumonia & ARDS, pneumonia & Normal \\
\hline 8 & 35 & 20 & M & Pneumonia, bronchitits, tracheitis & Bronchopneumonia, tracheitis & Normal \\
\hline 9 & 40 & 77 & M & Pneumonia & CMV infection & Normal \\
\hline 10 & 40 & 40 & M & Pneumonia & CMV infection & Normal \\
\hline
\end{tabular}

Abbreviations used: ARDS, adult respiratory distress syndrome; CMV, cytomegalovirus; SIDS, sudden infant death syndrome. 


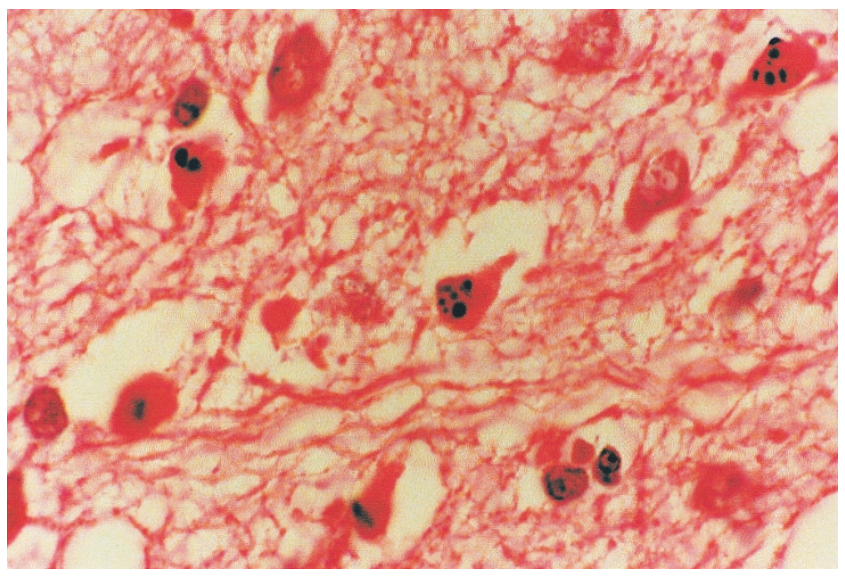

Figure 1. Histopathologic characteristics of PSN in pontine neurons demonstrating karyorrhexis (fragmentation of the nucleus), cell shrinkage, and eosinophilic cytoplasm (red). Hematoxylin and eosin staining, magnification $\times 1000$.

PSN with only a few surviving neurons revealing the characteristic hallmarks.

Immunohistochemistry and double labeling for Fas. Fas expression was clearly demonstrated by immunohistochemical techniques and was reliable in the human autopsy material, routinely fixed in formalin.

In cases without the histologic hallmarks of PSN, TUNEL staining revealed some Fas-positive cells throughout the hippocampus, the entorhinal cortex, and the basal pontine nuclei. Fas was present on cells with apoptotic morphology but also on histologically nonapoptotic cells. As confirmed by double labeling studies with NeuN, Fas-expressing cells were mainly neurons, but some GFAP-positive astrocytes and KiM1Ppositive microglial cells also demonstrated the binding of this receptor.

In cases of PSN, immunohistochemistry for Fas combined with TUNEL showed high Fas labeling for apoptotic cells. In early stages of PSN with marked apoptotic neuronal cell death, mainly neurons with normal appearing chromatin, chromatin condensation, or dense chromatin fragments showed positive Fas immunobinding. In later stages of apoptosis, cells with formation of apoptotic bodies were mostly negative for Fas staining (Fig. 2, $A$ and $B$ ). Many Fas-expressing astrocytes occurred in later stages of PSN when astrocytic gliosis had developed. Fas-positive cells were counted in the ventral pontine nuclei at the anatomic level of the locus ceruleus and in the subiculum at the level of the lateral geniculate body.

The total number of Fas-expressing cells was significantly higher when compared with cases without PSN ( $p=0.001)$; figures represent the percentage of Fas-immunopositive cells in relation to the total number of cells counted (Fig. $3 A$ ).

Fas-bearing cells were mainly NeuN-positive neurons, but GFAP-positive astrocytes and scattered KiM1P-positive microglial cells were also positive (Fig. 2, $C$ and $D$ ).

Immunohistochemistry and double labeling for Fas ligand. As demonstrated for the receptor, Fas ligand was also expressed on cells in the human autopsy brain tissue. Only a few Fas ligand-immunopositive cells, astrocytes, and microglial cells were detected in control brains whereas neurons stained negative.

Compared with cases without PSN, there was a slight but not significant increase in the percentage of Fas ligand-expressing cells in relation to the total number of cells in PSN brains counted in pons and subiculum. (Fig. 3B). As confirmed by double-labeling studies, Fas ligand-expressing cells were GFAP-positive astrocytes (Fig. 2E) and KiM1P-positive microglial cells (Fig. $2 F$ ). The majority of astrocytes expressed Fas ligand in later stages of PSN whereas microglial cells demonstrated Fas ligand expression in earlier stages of PSN. As only very few weakly positive cells were detected, we have been unable to clearly demonstrate neuronal expression of Fas ligand.

\section{DISCUSSION}

PSN necrosis is a distinct type of perinatal brain damage during a limited developmental period of the immature human brain. Although originally described by Friede (1) as neuronal necrosis, a recent reevaluation has provided evidence for a high amount of neuronal apoptotic cell death in the basal pontine nuclei and hippocampal subiculum (2). The present study aimed to investigate the role of the Fas/Fas ligand death receptor system, which is known to act as a proapoptotic stimulus not only in several animal models of hypoxiaischemia (27), but also in developmental physiologic apoptosis (18). Our study on PSN autopsy material demonstrated the marked expression of Fas receptor on pontine and pyramidal hippocampal neurons undergoing apoptosis. In contrast, Fas ligand expression was mainly on astrocytes and microglial cells. There was no significant up-regulation in PSN cases when compared with age-matched cases without the histologic hallmarks of PSN.

These results confirm and extend previous observations mainly resulting from adult animal models. The crucial role of the Fas/Fas ligand death receptor system in apoptotic cell death after ischemia has recently been shown and is also emphasized by the observation that lpr mice deficient in the Fas/Fas ligand pathway are highly resistant to ischemia-induced neuronal damage. Areas with the highest number of apoptotic cells in wild-type animals were found to be spared in Fas knockout mice, resulting in a clear reduction in the infarct volume (22). In a recent study in 14-d-old rats, the presence of Fas on neuronal cells in vitro and in vivo and its functionality as a death receptor when triggered by hypoxia-ischemia was clearly demonstrated (23). In the present study of human infants with PSN, Fas-immunoreactive neurons clearly exhibited the hallmarks of earlier apoptotic stages such as nuclear condensation and margination. In later stages of apoptosis, when free apoptotic bodies were present, cells did not stain positively for Fas. These findings broadly agree with previous observations made in the rat model of HII to the immature brain. A maximum of receptor up-regulation at 12 to $24 \mathrm{~h}$ after the injury corresponded to the maximum amount of TUNEL-positive apoptotic cells at these points. At later time (48 h), the number of Fas-positive cells was significantly lower in this model (23).

In cases without PSN a small number of Fas and Fas ligand-bearing cells were detected. These observations were 

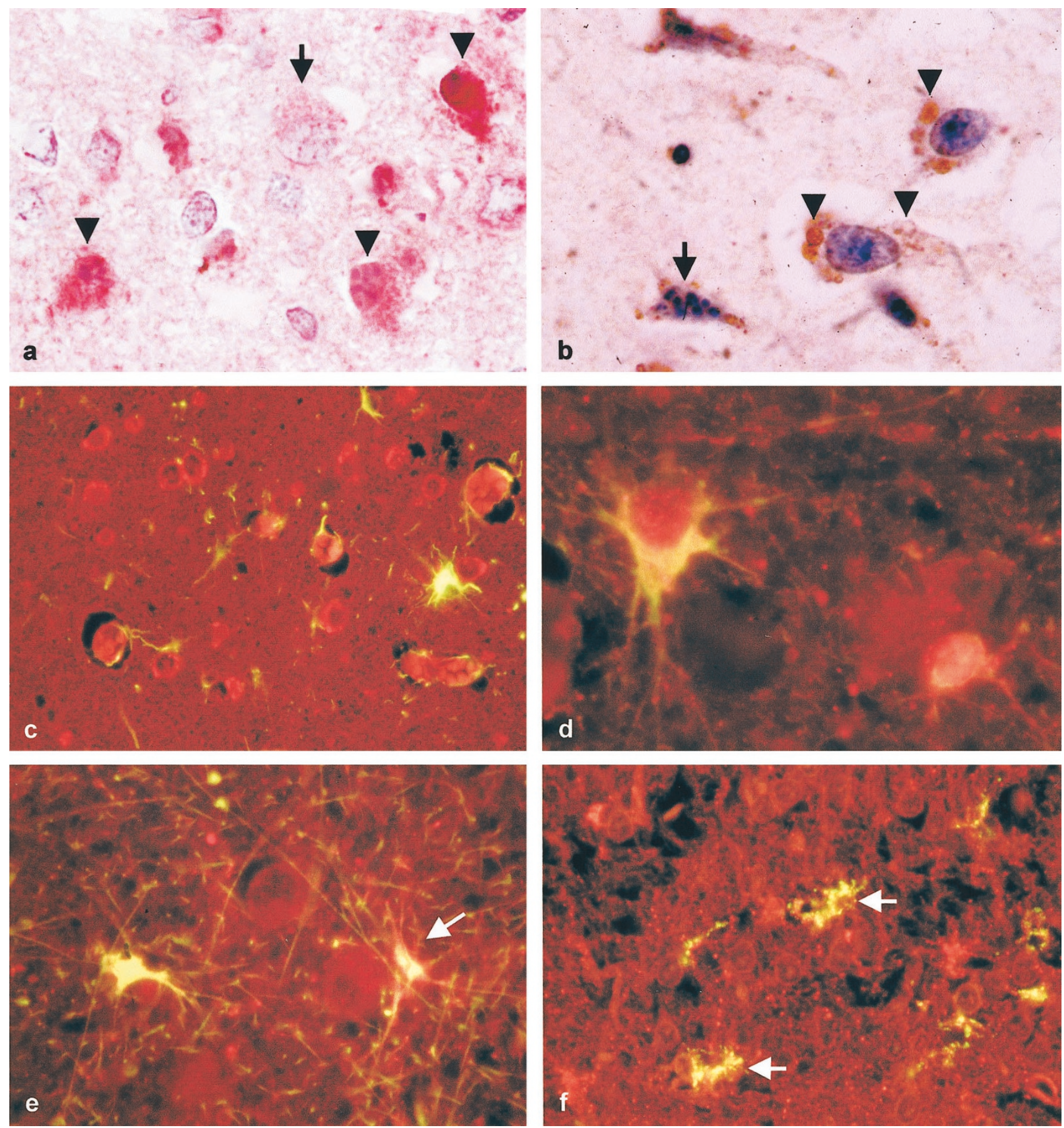

Figure 2. Light microscopy: $A$, in PSN cases, most TUNEL-positive apoptotic cells (black nuclei) express Fas receptor (red cytoplasm). Apoptotic bodies stain negative. Arrowheads indicate double-labeled cells, whereas the arrow shows a Fas-positive, TUNEL-negative neuron. Pons, magnification $\times 1000$. $B$, apoptotic cells (arrows) and normal appearing neurons (arrowheads) demonstrate Fas receptor expression (brown), in particular in cytoplasmic vesicles. Apoptotic bodies stain negative for Fas. Subiculum, magnification $\times 1000$. Fluorescence microscopy: $C$, Fas receptor expression (red) is mainly detected in neurons and also in some GFAP-positive astrocytes (green). Pons, magnification $\times 400$. $D$, astrocytes coexpressing GFAP and Fas. Subiculum, magnification $\times 1000$. $E$, double labeling reveals astrocytic coexpression of GFAP (green) and Fas ligand (red), whereas neurons do not stain. Pons, magnification $\times 1000$. $F$, in earlier stages of PSN, Fas ligand expression of KiM1P-positive microglia was observed. Subiculum, magnification $\times 400$.

previously made in rat hippocampal and cortical neurons cultured from postnatal $\mathrm{d} 0$ as well as in the developing rat brain up to postnatal d 14 in vivo, possibly indicating that adult brain cell numbers may be established in part by receptor-mediated cell suicide initiated by in situ Fas ligand-bearing cells (18, 23). Our present results obtained in infants with PSN thereby may also suggest a role for this receptor in both human physiologic and pathologic apoptosis. For ethical reasons we were unable to obtain control tissue other than from sick infants. Therefore, we cannot exclude an overestimation of apoptotic as well as of Fas-positive cells in cases without the histologic criteria of PSN.

PSN is found under a wide range of pathologic conditions including perinatal anoxia, ischemia (28), hypoglycemia, hy- 


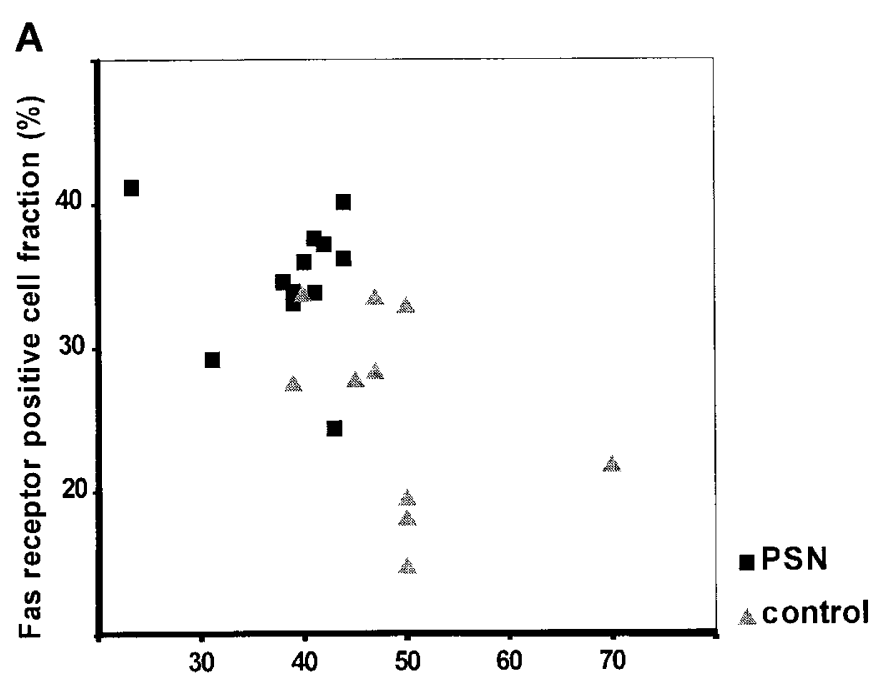

postmenstrual age (weeks)

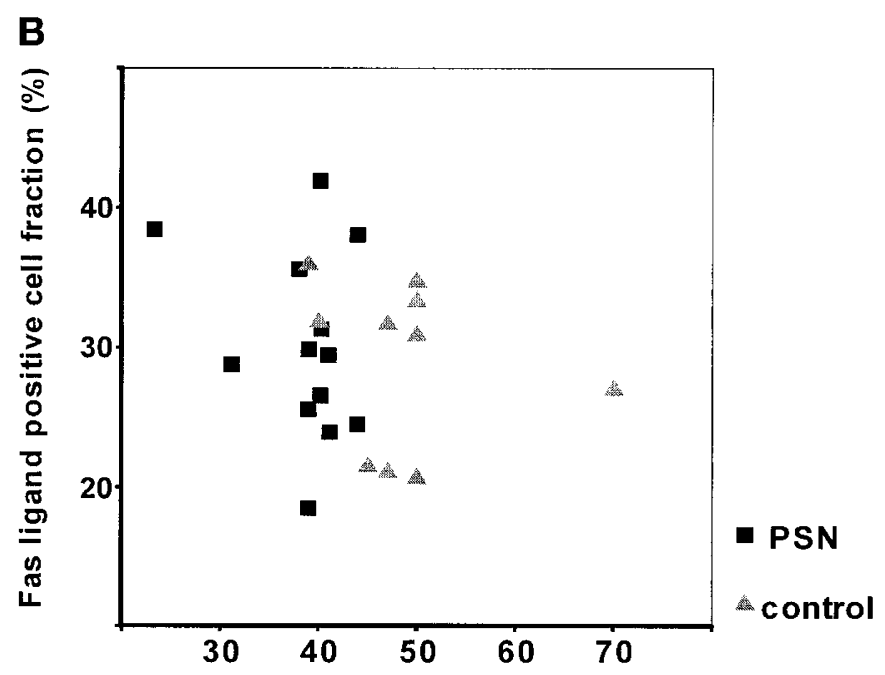

postmenstrual age (weeks)

Figure 3. Fas receptor and Fas ligand expression in PSN cases (black) and controls (gray) determined in pons (ventral nuclei, level of the locus ceruleus) and subiculum (level of the lateral geniculate body). Figures represent the percentage of immunopositive cells in relation to the total number of cells counted. $A$, amount of Fas receptor-positive cells is significantly higher in PSN cases $(p=0.001)$ than in controls. $B$, Fas ligand expression does not differ between PSN and cases without PSN.

peroxygenation, and the production of oxygen-derived free radicals (29). However, the underlying molecular mechanisms are still not fully understood. Mitani and coworkers (30) have related a functional change of $N$-methyl-D-aspartate receptors in the pontine nucleus of rats at postnatal $\mathrm{d} 1-30$ to the enhancement of susceptibility to neurotoxicity. Taking the observations on PSN cases into account, it further remains to be clarified whether those Fas-positive cells detected in control brains are more susceptible to injurious stimuli such as hypoxia, hyperoxia, or hypoglycemia. Both spontaneous and induced apoptotic cell death may be increased in certain brain areas during a specific period in human brain development. The identification of inductive but also protective stimuli may prove useful in the investigation of the underlying cause of this disorder. A recent study on PSN cases demonstrated the expression of activated caspase 3 and poly(ADP ribose) polymerase (PARP) in apoptotic cells, confirming the involvement of proapoptotic factors in this pathologic entity (31).

Several intrinsic protection systems such as $\mathrm{Cu} / \mathrm{Zn}$ superoxide dismutase and apo $\mathrm{E}$ have been identified in neonates with PSN, suggesting that these factors may be produced by astrocytes and taken up by neurons on membrane remodeling during early responses to cerebral hypoxic or ischemic insults in PSN neonates $(32,33)$.

The role of Fas ligand remains a matter of discussion. Applying immunohistochemistry techniques, Fas ligand expression on astrocytes has been previously reported in the normal mouse, rat, and adult human CNS but also in brain pathology such as tumors and multiple sclerosis $(34,35)$. Bechmann and coworkers (36) have recently demonstrated Fas ligand-bearing astrocytes and neurons in the normal brain protecting the tissue from self-damaging immune attacks by forming an immunologic brain barrier. However, we have been unable to clearly demonstrate neuronal expression of Fas ligand in the human autopsy material investigated. As Fas ligand is subject to proteolytic cleavage resulting in its release from the cell surface, cell surface membrane expression may be detected in freshly fixed tissue but not after several hours or days have elapsed between death and fixation. Only a few weakly positive neurons were detected, possibly indicating an autocrine mechanism in the Fas/Fas ligand pathway (37).

Further studies will be needed to elucidate the function of the Fas/Fas ligand system in physiologic and pathologic apoptosis in the developing human brain. Should the pivotal role for this system be confirmed, novel therapeutic approaches directed toward blocking the Fas-specific apoptotic signaling pathway such as caspase inhibition (38-40) might prove useful for preventing neuronal loss after injury to the developing brain.

\section{REFERENCES}

1. Friede RL 1972 Ponto-subicular lesions in perinatal anoxia. Arch Pathol 94:343-354

2. Brück Y, Brück W, Kretzschmar HA, Lassmann H 1996 Evidence for neuronal apoptosis in pontosubicular neuron necrosis. Neuropathol Appl Neurobiol 22:23-29

3. Wyllie AH, Duvall E 1992 Cell injury and death. In: McGee JO, Isacsson PG, Wright NA (eds) Oxford Textbook of Pathology, Oxford University Press, Oxford, pp 141-193

4. Yue X, Mehmet H, Penrice J, Cooper C, Cady E, Wyatt JS, Reynolds EO, Edwards AD, Squier MV 1997 Apoptosis and necrosis in the newborn piglet brain following transient cerebral hypoxia-ischaemia. Neuropathol Appl Neurobiol 23:16-25

5. Sidhu RS, Tuor UI, Del Bigio MR 1997 Nuclear condensation and fragmentation following cerebral hypoxia-ischemia occurs more frequently in immature than older rats. Neurosci Lett 223:129-132

6. Joashi UC, Greenwood K, Taylor DL, Kozma M, Mazarakis ND, Edwards AD, Mehmet H 1999 Poly(ADP ribose) polymerase cleavage precedes neuronal death in the hippocampus and cerebellum following injury to the developing rat forebrain. Eur J Neurosci 11:91-100

7. Edwards AD, Yue X, Cox P, Hope PL, Azzopardi DV, Squier MV, Mehmet H 1997 Apoptosis in the brains of infants suffering intrauterine cerebral injury. Pediatr Res 42:684-689

8. Kato H, Kogure K, Liu X-H, Araki T, Itoyama Y 1996 Progressive expression of immunomolecules on activated microglia and invading leucocytes following focal cerebral ischemia in the rat. Brain Res 734:203-212

9. Silverstein F, Barks J, Hagan P, Liu X, Ivacko J, Szaflarski J 1997 Cytokines and perinatal brain injury. Neurochem Int 30:375-383

10. Lee JM, Grabb MC, Zipfel GJ, Choi DW 2000 Brain tissue responses to ischemia. $\mathrm{J}$ Clin Invest 106:723-731

11. Nagata S, Golstein P 1995 The Fas death factor. Science 267:1449-1456 
12. Kischkel FC, Hellbardt S, Behrmann I, Germer M, Pawlita M, Krammer PH, Peter ME 1995 Cytotoxicity-dependent APO-1 (Fas/CD95)-associated proteins form a death-inducing signaling complex (DISC) with the receptor. EMBO J 14:5579-5588

13. Aggarwal BB, Singh S, LaPushin R, Totopal K 1995 Fas antigen signals proliferation of normal human diploid fibroblasts and its mechanism is different from tumor necrosis factor receptor. FEBS Lett 364:5-8

14. Griffith TS, Brunner T, Fletcher SM, Green DR, Ferguson TA 1995 Fas ligandinduced apoptosis as a mechanism of immune privilege. Science 270:1189-1192

15. French LE, Hahne M, Viard I, Radlgruber G, Zanone R, Becker K, Müller C, Tschopp J 1996 Fas and Fas ligand in embryos and adult mice: ligand expression in severa immune-privileged tissues and coexpression in adult tissues characterized by apoptotic cell turnover. J Cell Biol 133:335-343

16. Streilein JW 1995 Unraveling the immune privilege. Science 270:1158-1159

17. Holler N, Zaru R, Micheau O, Thome M, Attinger A, Valitutti S, Bodmer JL, Schneider P, Seed B, Tschopp J 2000 Fas triggers an alternative, caspase-8independent cell death pathway using the kinase RIP as effector molecule. Nat Immunol 1:489-495

18. Cheema ZF, Wade SB, Sata M, Walsh K, Sohrabji F, Miranda RC 1999 Fas/Apo [apoptosis]-1 and associated proteins in the differentiating cerebral cortex: induction of caspase-dependent cell death and activation of NF-kappaB. J Neurosci 19:1754-1770

19. Nilsen J, Mor G, Naftolin F 2000 Estrogen-regulated developmental neuronal apoptosis is determined by estrogen receptor subtype and the Fas/Fas ligand system. J Neurobiol 43:64-78

20. Nishimura T, Akiyama H, Yonehara S, Kondo H, Ikeda K, Kato H, Iseki E, Kosaka K 1995 Fas antigen expression in brains of patients with Alzheimer-type dementia. Brain Res 695:137-145

21. Dowling P, Shang G, Sumul R, Menonna J, Cook S, Husar W 1996 Involvement of the CD95 (APO-1/Fas) receptor/ligand system in the multiple sclerosis brain. J Exp Med 184:1513-1518

22. Martin-Villalba A, Herr I, Jeremias I, Hahne M, Brandt R, Vogel J, Schenkel J, Herdegen T, Debatin KM 1999 CD95 ligand (Fas-L/APO-1L) and tumor necrosis factor-related apoptosis-inducing ligand mediate ischemia-induced apoptosis in neurons. J Neurosci 19:3809-3817

23. Felderhoff-Mueser U, Taylor DL, Greenwood K, Kozma M, Stibenz D, Joashi UC, Edwards AD, Mehmet H 2000 Fas/CD95/APO-1 can function as a death receptor for neuronal cells in vitro and in vivo and is upregulated following cerebral hypoxicischemic injury to the developing rat brain. Brain Pathol 10:17-29

24. Hunt N, Attanoos R, Jasani B 1996 High temperature retrieval and loss of nuclear morphology: a comparison of microwave and autoclave techniques. J Clin Pathol 49:767-770

25. Gold R, Schmied M, Giegerich G, Breitschopf H, Hartung HP, Toyka K, Lassmann H 1994 Differentiation between cellular apoptosis and necrosis by combined use of TUNEL and nick translation techniques. Lab Invest 71:219-225
26. Stadelmann C, Brück W, Bancher C, Jellinger K, Lassmann H 1998 Alzheimer disease: DNA fragmentation indicates increased neuronal vulnerability, but not apoptosis. J Neuropathol Exp Neurol 57:456-464

27. Matsuyama T, Hata R, Yamamoto Y, Tagaya M, Akita H, Uno H, Wanaka A, Furuyama J, Sugita M 1995 Localisation of Fas antigen mRNA induced in postischemic murine forebrain by in situ hybridisation. Mol Brain Res 34:166-172

28. Mito T, Kamei A, Takashima S, Becker LE 1993 Clinicopathological study of pontosubicular necrosis. Neuropediatrics 24:204-207

29. Skullerud K, Skjaeraasen J 1988 Clinicopathological study of germinal matrix hemorrhage, pontosubicular necrosis, and periventricular leukomalacia in stillborn. Childs Nerv Syst 4:88-91

30. Mitani A, Watanabe M, Kataoka K 1998 Functional change of NMDA receptors related to enhancement of susceptibility to neurotoxicity in the developing pontine nucleus. J Neurosci 18:7941-7952

31. Stadelmann C, Mews I, Srinivasan A, Deckwerth TL, Lassmann H, Brück W 2001 Expression of cell death-associated proteins in neuronal apoptosis associated with pontosubicular necrosis. Brain Pathol 11:273-281

32. Arai Y, Mizuguchi M, Ikeda K, Takashima S 1996 Transient expression of apolipoprotein-E in neonates with pontosubicular neuron necrosis. Acta Neuropathol (Berl) 91:396-399

33. Ozawa H, Fukuda T, Nishida A, Takashima S $1997 \mathrm{Cu}, \mathrm{Zn}$-superoxide dismutase reaction in neonatal pontosubicular neuron necrosis. Pediatr Neurol 16:126-130

34. Saas P, Walker PR, Hahne M, Quiquerez AL, Schnuriger V, Perrin G, French L, Van Meir EG, de Tribolet N, Tschopp J, Dietrich PY 1997 Fas ligand expression by astrocytoma in vivo: maintaining immune privilege in the brain? J Clin Invest 99:1173-1178

35. Ouallet J, Baumann N, Marie Y, Villarroya H 1999 Fas system up-regulation in experimental autoimmune encephalomyelitis. J Neurol Sci 170:96-104

36. Bechmann I, Mor G, Nilsen J, Eliza M, Nitsch R, Naftolin F 1999 FasL (CD95L, Apo1L) is expressed in the normal rat and human brain: evidence for the existence of an immunological brain barrier. Glia 27:62-74

37. Siegel RM, Chan FKM, Chun HJ, Lenardo MJ 2000 The multifaceted role of Fas signaling in immune cell homeostasis and autoimmunity. Nat Immunol 1:469474

38. Cheng Y, Deshmukh M, D'Costa A, Demaro JA, Gidday JM, Shah A, Sun Y, Jacquin MF, Johnson EM, Holtzman DM 1998 Caspase inhibitor affords neuroprotection with delayed administration in a rat model of neonatal hypoxic-ischemic brain injury. J Clin Invest 101:1992-1999

39. Braun JS, Novak R, Herzog KH, Bodner SM, Cleveland JL, Tuomanen EI 1999 Neuroprotection by a caspase inhibitor in acute bacterial meningitis. Nat Med $5: 298-302$

40. Nicholson DW 2000 From bench to clinic with apoptosis-based therapeutic agents. Nature 407:810-816 